\title{
Design of the Next Generation Aircraft Noise Prediction Program: ANOPP2
}

\author{
Leonard V. Lopes* and Casey L. Burley ${ }^{\dagger}$ \\ NASA Langley Research Center, Hampton, Virginia, 23681
}

\begin{abstract}
The requirements, constraints, and design of NASA's next generation Aircraft NOise Prediction Program (ANOPP2) are introduced. Similar to its predecessor (ANOPP), ANOPP2 provides the U.S. Government with an independent aircraft system noise prediction capability that can be used as a stand-alone program or within larger trade studies that include performance, emissions, and fuel burn. The ANOPP2 framework is designed to facilitate the combination of acoustic approaches of varying fidelity for the analysis of noise from conventional and unconventional aircraft. ANOPP2 integrates noise prediction and propagation methods, including those found in ANOPP, into a unified system that is compatible for use within general aircraft analysis software. The design of the system is described in terms of its functionality and capability to perform predictions accounting for distributed sources, installation effects, and propagation through a non-uniform atmosphere including refraction and the influence of terrain. The philosophy of mixed fidelity noise prediction through the use of nested Ffowcs Williams and Hawkings surfaces is presented and specific issues associated with its implementation are identified. Demonstrations for a conventional twin-aisle and an unconventional hybrid wing body aircraft configuration are presented to show the feasibility and capabilities of the system. Isolated model-scale jet noise predictions are also presented using high-fidelity and reduced order models, further demonstrating ANOPP2's ability to provide predictions for model-scale test configurations.
\end{abstract}

\section{Introduction}

Community noise has been an ongoing problem for aircraft and is projected to be a major concern in the future due to increased air traffic. ${ }^{1}$ NASA's Fundamental Aeronautics Program (FAP) and Integrated Systems Research Program (ISRP) contain projects that address aircraft noise issues through breakthrough technologies for current and future aircraft configurations. ${ }^{2,3}$ Both conventional and unconventional aircraft designs continue to be evaluated, ${ }^{4}$ where assessments are performed using aircraft noise prediction and measured data if available. The accuracy of the assessments, particularly for unconventional aircraft, where measurement data is typically non-existent, rely solely on the prediction. Hence, any comprehensive aircraft noise prediction method must contain the capability for application to new designs and the reliability to predict outside of the current experience base.

NASA initiated the development of the Aircraft NOise Prediction Program (ANOPP) ${ }^{5,6}$ approximately 30 years ago to provide the U.S. Government with the ability to assess aircraft noise. The prediction methodologies that have been implemented within ANOPP were developed as empirical or semi-empirical models, using the best available experimental data sets and acoustic prediction methods. Many of the prediction methods work well for conventional aircraft configurations but lack capability and fidelity required for non-conventional configurations. The recent push for unconventional aircraft designs requires more robust, higher-fidelity, physics-based noise prediction tools that can predict outside of the experience base for which ANOPP was designed.

ANOPP2 is designed to accurately predict noise from current and future concept aircraft and propulsion systems. Figure 1(a) shows a conventional tube-and-wing aircraft configuration with rear mounted engines.

*Research Aerospace Engineer; Aeroacoustics Branch, MS 461, Member AIAA; leonard.v.lopes@nasa.gov

†Senior Research Scientist, Aeroacoustics Branch, MS 461, Member AIAA; casey.l.burley@nasa.gov 
A tube-and-wing design typically includes noise from the engines and airframe components such as the landing gear and flaps. Prediction of these sources in isolation is not the same as installed. For example, the noise from landing gear is directly related to the local flow field, which is affected by the freestream flow velocity and the aircraft's high-lift system settings for an installed main gear. ${ }^{7-9}$ This flowfield can be significantly different from the uniform freestream flow velocity often assumed in empirical methods. Similarly, the engine noise sources can be reflected from the wing for under-the-wing configurations, or partly shielded for over-the-wing configurations. These effects, as well as other source noise phenomena, are more evident for unconventional configurations as shown in Figure 1(b). This Hybrid Wing Body (HWB) design offers significant noise reduction potential due to shielding of the engine sources by the aircraft airframe. A study by Thomas et al. ${ }^{4}$ combined prediction with measured shielding data to give a noise assessment of such a configuration. The noise reduction potential was shown to be on the order of NASA's Environmentally Responsible Aviation (ERA) project goal of $42 \mathrm{~dB}$ cumulative below Stage 4 certification level. $^{3}$ The prediction of the noise from this configuration using ANOPP required extrapolation of the empirical prediction methods beyond the data base for which they were built.

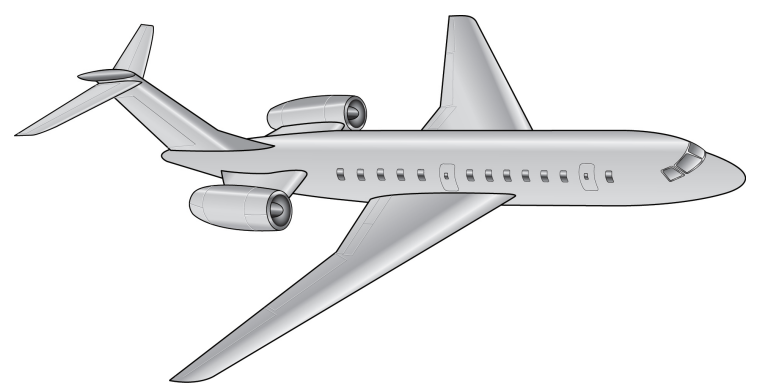

(a) Conventional tube-and-wing aircraft design.

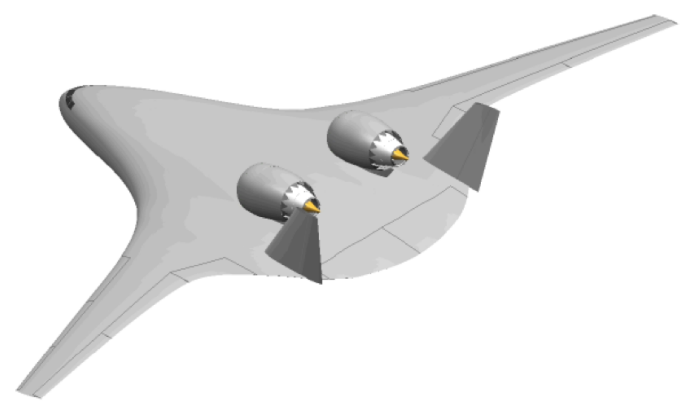

(b) Unconventional N+2 Hybrid Wing Body (HWB) concept.

Figure 1. Conventional and unconventional aircraft designs,

The next generation ANOPP, called ANOPP2, will provide the capability and a framework to integrate acoustic approaches for source noise component prediction, installation effects, and propagation to the farfield. The predictions from ANOPP2 will include the fidelity and flexibility required to predict outside any experience base that currently exists. A focal point of ANOPP2 is a combination of acoustic approaches; that is, to offer several options for a specific noise mechanism depending on requested fidelity and execution speed. This allows ANOPP2 to include fast prediction methods for design optimization while including prediction methods that contain the fidelity required for understanding and provide insight into controlling noise physics.

In this paper, the objectives, requirements, and constraints are presented, and the philosophy of the noise predictions within the ANOPP2 system is explored. The design of the system is described in terms of its functionality and capability to perform predictions accounting for distributed sources, scattering of sound by the aircraft, and propagation through a non-uniform atmosphere including refraction and the influence of terrain. Issues associated with integrating acoustic approaches of differing fidelity in a unified system are discussed. ANOPP2 predictions are presented for both a conventional and unconventional aircraft in flight, in order to demonstrate the ability of ANOPP2 to meet the requirements and constraints.

\section{ANOPP2: Goal, Objectives, and Constraints}

Similar to ANOPP, the goal of ANOPP2 is to provide the U.S. Government with the ability to independently: (1) assess aircraft system noise; (2) assess aircraft component noise; and (3) evaluate aircraft noise reduction technologies and flight procedures. Additionally, ANOPP2 is to provide a capability for understanding the noise physics in support of potential experiments and flight demonstration activities. The major objectives of ANOPP2 are summarized as: 


\section{Objectives}

- Provide the capability to predict the noise from arbitrary aircraft designs, including conventional and unconventional aircraft designs of full-scale and model-scale size, as well as Unmanned Aerial Vehicles (UAVs), Personal Aerial Vehicles (PAVs), and other external acoustic applications.

- Establish a framework where a combination of acoustic prediction methods of varied fidelity can communicate in a unified system. This ranges from fast computations with reduced order models for system level assessment and design to potentially computationally intensive, high-fidelity, physics-based methods for investigating and understanding noise generation and propagation effects at the component and aircraft system level. A sampling of methods for consideration are shown in Fig. 2.

- Include acoustic effects for comparison to flight and model-scale test data such as flight test environment, Doppler effects, convective amplification, and propagation.

- Include physics based prediction of Propulsion Airframe Aeroacoustics $\left(\mathrm{PAA}^{10}\right)$, airframe interaction effects such as scattering of undercarriage noise by the airframe, and propulsion interactions like those seen in closely spaced twin jets or open-rotors.

- Provide capability to assess noise reduction technologies and approaches. Provide standards, benchmarks, and evaluations of component noise prediction.

\section{Semi-Empirical Fidelity Highly Computational}

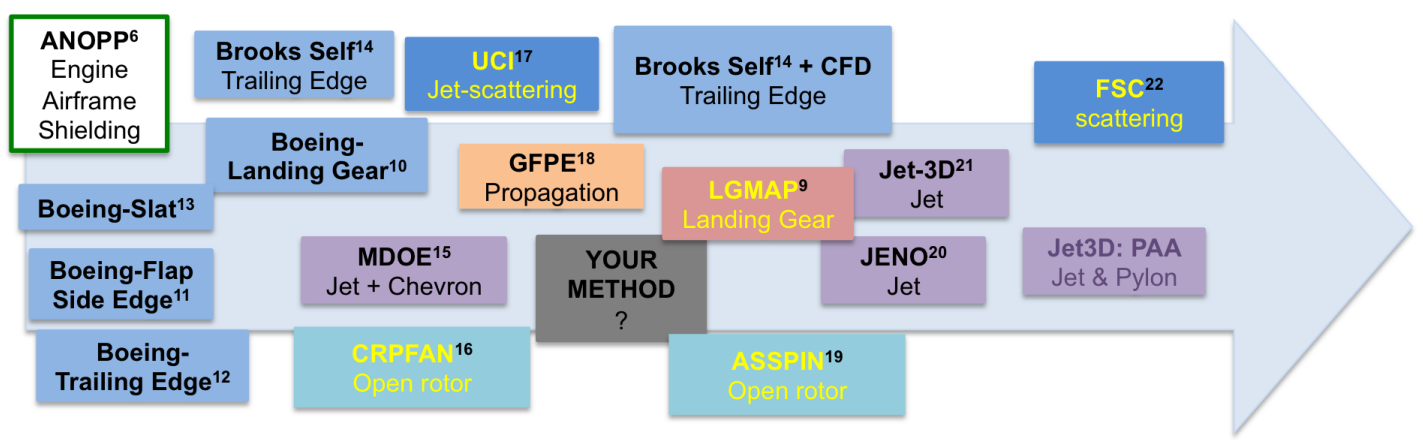

Figure 2. Prediction and propagation methods being considered for implementation in ANOPP2. ${ }^{6,8,9,11-22}$ Methods range from semi-empirical, low-fidelity methods to high-fidelity, computationally intensive methods.

ANOPP2 must also satisfy several major constraints. These fall into 9 categories; performance, modularity, reliability, interoperability, extensibility, portability, maintainability, usability, and scalability. Below is a brief description of each constraint and how it pertains to the ANOPP2 system.

\section{Constraints}

PERFORMANCE: ANOPP2 must provide a framework to accommodate noise prediction methods that range from physics-based, high-fidelity, and potentially computationally intensive to semi-empirical, lower fidelity, and computationally efficient. The framework must meet requirements that include efficiency and performance metrics such as computer memory and computational time.

MODULARITY: ANOPP2 must be modular enabling the user to tailor the computational components of their prediction toward efficiency, fidelity, and accuracy needs. The system must contain a user-friendly interface that facilitates switching between methods of differing fidelity when desired. This may occur as the user desires, or as a function of some trigger such as component contribution to the overall noise.

RELIABILITY: The ANOPP2 software must allow for prediction and propagation methods of varying developmental maturity and, as such, may contain methods that are unreliable and/or invalid for certain operating conditions. ANOPP2 must have capabilities to allow for sensitivity studies and uncertainty analysis for different prediction and propagation methods. This will enable a user to understand the risks and benefits of choosing one noise prediction or propagation method over another. 
INTEROPERABILITY: ANOPP2 must contain interoperability functionality to enable integration with analysis software such as the FAA's Environmental Design Space (EDS ${ }^{23}$ and NASA's OpenMDAO ${ }^{24}$ and GEN2 toolset. $^{25}$ ANOPP2 must contain library functions, in the form of Application Programming Interfaces (APIs), that provide functionality such as signal processing and acoustic analysis and noise metrics to be available for use by the ANOPP2 user community.

EXTENSIBILITY: The ANOPP2 system is required to predict for current and future aircraft, and, as such, must be extensible to allow implementation of current and future noise source prediction and propagation methods. The system must contain a suite of tools and instructions for users to efficiently incorporate their prediction and/or propagation methods seamlessly into the system.

PORTABILITY: ANOPP2 must be portable to accommodate different computer architectures and operating environments (currently Mac, PC, and Linux) and be distributable for use by the U.S. Government, academia, and industries. Since ANOPP2 can potentially contain proprietary methods, the system must be configurable to allow for customized distributions depending on the user.

MAINTAINABILITY: ANOPP has been in use for approximately 30 years, serving as the benchmark for aircraft noise prediction. To be as successful as its predecessor, ANOPP2 must be robust and dependable for many years. For this reason, ANOPP2 must be designed for long term needs and contain self verification software, which allows for continued development with reduced risk of contaminating existing components.

USABILITY: The ANOPP2 software must be documented and distributed with a suite of manuals to aid in using the noise prediction and propagation modules. It is expected that a user of ANOPP2 is familiar with acoustics, hence the manuals serve as a bridge between the user's familiarity with acoustics and the theoretical base of the chosen prediction methods.

SCALABILITY: ANOPP2 contains methods that require a range of computer resources from single processors to multiple processors in the form of integration methods, source-time-dominant vs. reception-time-dominant for optimized execution, and parallelization options, including Message Passing Interface (MPI), ${ }^{26}$ Open Multi-Processing (OpenMP), ${ }^{27}$ and, ultimately, a self-optimizing combination of both.

\section{ANOPP2 Prediction Approach}

The challenge for the ANOPP2 framework is the integration of noise prediction methods of varying fidelity into a unified system. Figure 3 shows three stages for an aircraft noise prediction: source noise generation, installation effects, and effects of atmosphere and terrain. Each of the three stages of a single prediction may be of differing fidelity and the full aircraft prediction may contain many single predictions, one for each noise generating mechanism. The challenge is weaving together a mixture of methods of varying fidelity, herein called mixed-fidelity noise prediction, into a unified system.

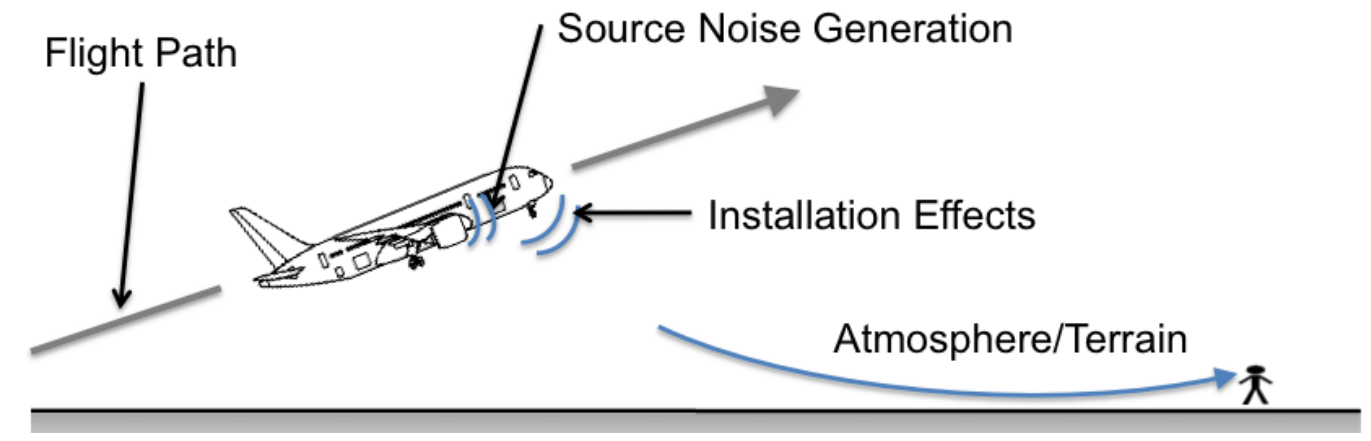

Figure 3. The capabilities of ANOPP2 include: engine and airframe source noise prediction such as inlet noise (shown), installation effects including scattering and shielding, and propagation from near the aircraft towards the observer on the ground including the effects of the atmosphere and terrain.

ANOPP2 addresses this challenge through the use of nested acoustic data surfaces which allow the communication between methods of different fidelity. This includes data surfaces where only acoustic pressure 
is defined, such as those in ANOPP, and data surfaces where acoustic pressure and velocity are defined, such as Ffowcs Williams and Hawkings (FW-H) surfaces. ${ }^{28}$ For many years, FW-H surfaces have been used for acoustic applications ${ }^{29}$ and will represent the highest fidelity data surface available in ANOPP2. The pressure and velocity on a FW-H surface completely define all noise sources contained inside to any observer outside the surface. The FW-H technique has been successfully used to predict noise by coupling Computational Fluid Dynamics (CFD) and a FW-H solver ${ }^{30-33}$ to provide the noise at the observer. As long as nonlinear effects, such as shocks that cause High Speed Impulsive (HSI) noise in helicopters, ${ }^{34}$ and volume sources, such as turbulence in jet exhausts, ${ }^{35}$ are inside the surface, their contribution to the far-field noise is defined by the conditions on the surface. By using the conditions on the surface as input into a FW-H solver, the computation is reduced to a manageable surface integration without direct knowledge of the complicated sound source inside. Within ANOPP2, pressure data surfaces are used for low-fidelity methods, such as ANOPP or empirically based methods, and FW-H surfaces are used with higher-fidelity methods, such as those based on CFD.

Figure 4 schematically shows the nested data surface approach implemented in ANOPP2. Several acoustic Source-Surfaces are shown around aircraft noise components, which are nested within the acoustic MidSurface that surrounds the aircraft. The Source- and Mid-Surfaces are not restricted to spheres as shown in Fig 4, but can be arbitrarily shaped, allowing for inclusion of distributed sources such as those associated with the jet exhaust. The component source noise prediction, regardless of the acoustic approach, is wrapped in a Source-Surface. There can be several Source-Surfaces, one for each unique source or subset of sources. The Source-Surface is provided as input to the method that calculates the noise on the Mid-Surface. This method can include the fidelity to account for PAA or non-linear effects. The noise on the Mid-Surfaces, one for each unique Source-Surface, can be summed or kept separate. Since the Mid-Surface is a penetrable FW-H surface, several Mid-Surfaces can be added together and still retain the constructive/destructive interference of the acoustic sources. The Far-Surface is placed in the far-field at the observer location(s). Once the noise is defined on the Far-Surface it is then summed and the result is the total noise at the observer. It should be noted that many source noise methods currently provide only acoustic pressure, therefore the acoustic velocity, required by the FW-H surface, will need to be provided. This is accomplished by the method or calculated by ANOPP2 directly.

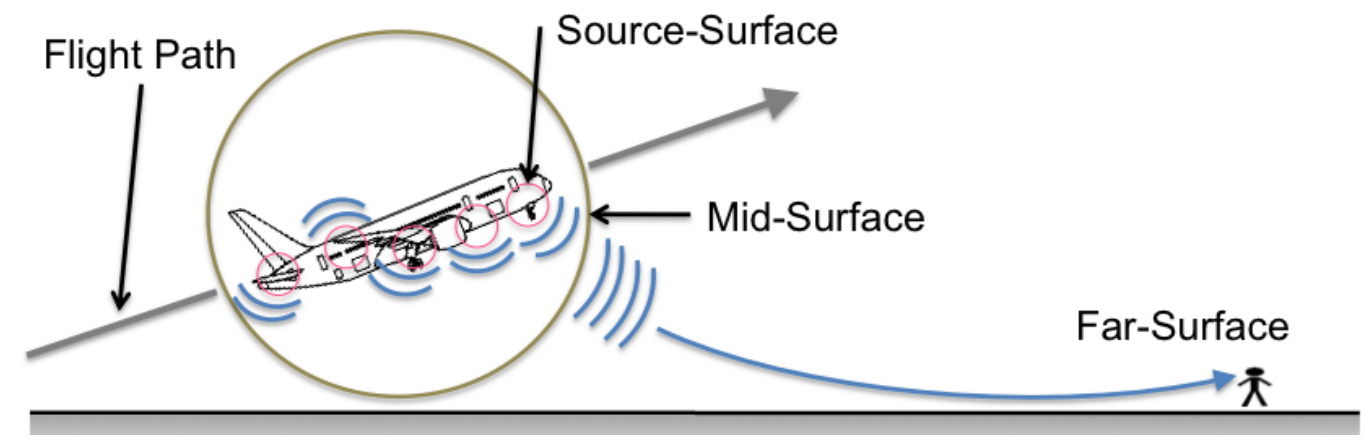

Figure 4. Representation of the FW-H surfaces in the ANOPP2 prediction system. The Source-Surface surrounds source or subset of sources; Mid-Surface surrounds aircraft; and Far-Surface is on the ground.

Figure 5 shows the information flow within ANOPP2. The information about the aircraft and flight path, including scattering geometry, is provided as input to a reservoir of information, labeled the 'Flight Condition.' The Flight Condition can be queried to provide information required by methods that predict noise on a Source-Surface. The noise on this surface is provided as input, along with the Flight Condition, to prediction methods that handle the installation effects. These method(s) calculate the propagation of the noise from the Source-Surface to the Mid-Surface. The noise on the Mid-Surfaces are then provided as input to the method that accounts for the atmosphere and terrain effects, including the effects of the ground and elevation. These methods propagate the noise from the Mid-Surface to the far-field observer or to a position on the Far-Surface.

The execution path of ANOPP2, by design, is highly configurable. Figure 6 shows two example configurations. In Fig. 6(a), the installation effects have been omitted from the general form, shown in Fig. 5. The source noise prediction method provides the noise directly onto the Mid-Surface, skipping the Source-Surface and omitting the Source-Surface propagation method, which accounts for installation effects. This configu- 


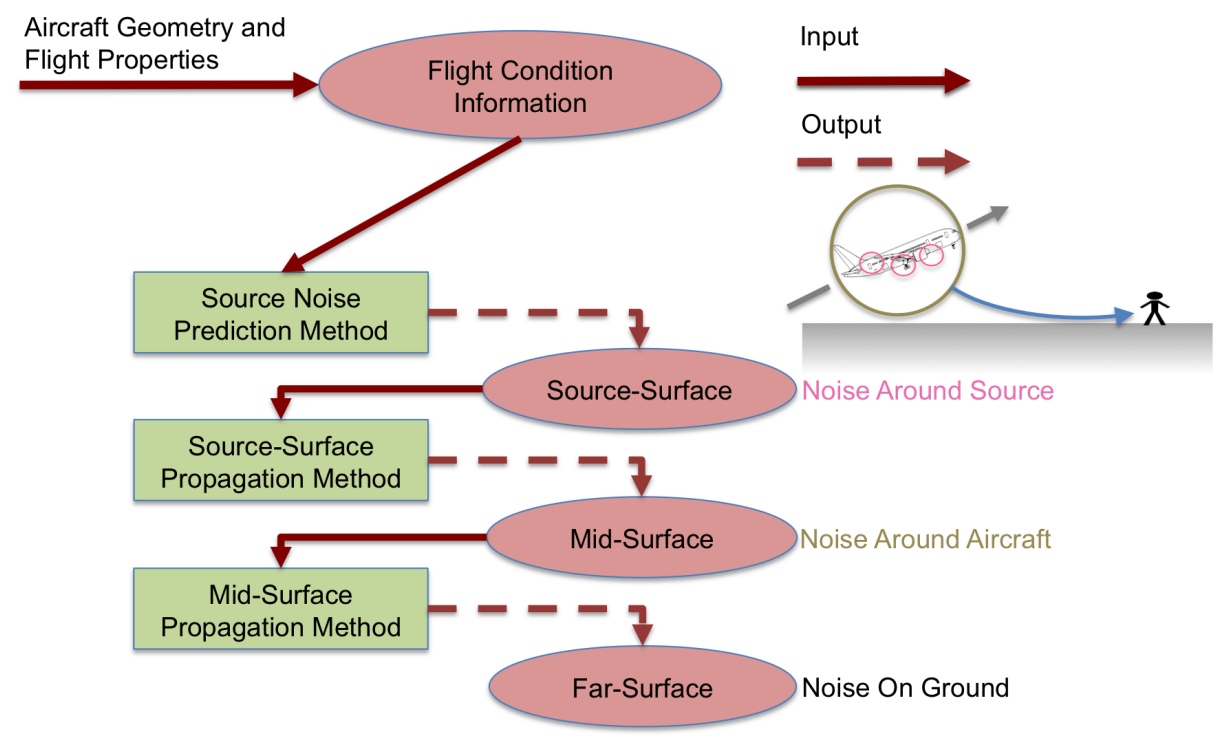

Figure 5. Information flow diagram for a single ANOPP2 component noise prediction.

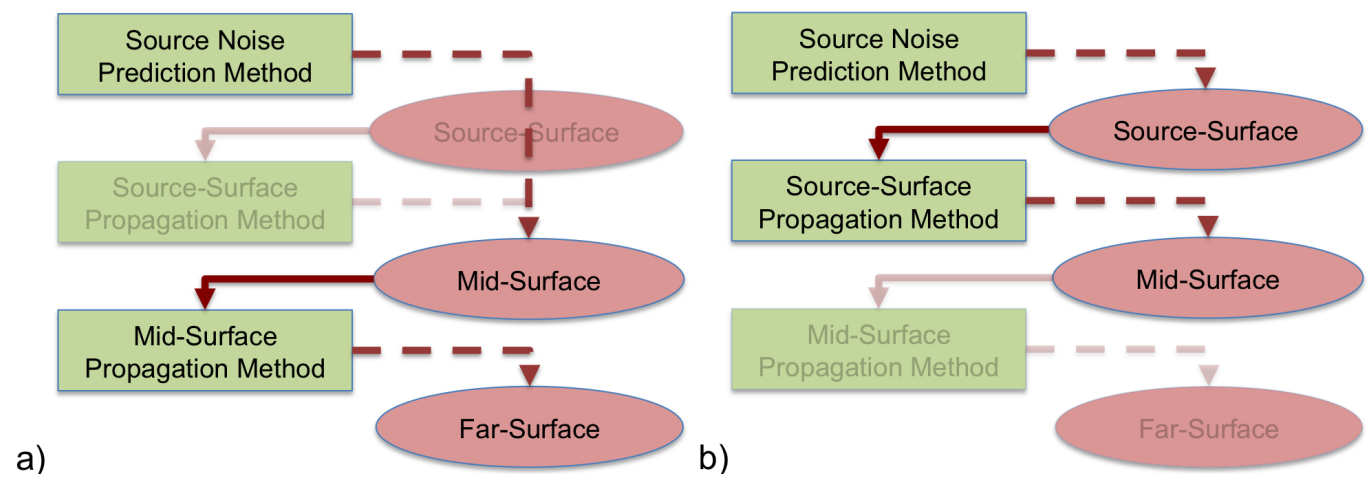

Figure 6. Demonstration of omitting modules in a noise prediction. The user has the option to a) exclude the Source-Surface or b) stop the calculation at the Mid-Surface or Source-Surface for analysis or comparison to experimental data.

ration is typical for current approaches, i.e. ANOPP. A second configuration example is shown in Fig. 6(b). In this configuration, the user has opted to analyze the noise at the Mid-Surface. This configuration would be used when comparing ANOPP2 noise predictions to model-scale measurements.

\section{ANOPP2 Architecture}

The ANOPP2 software components are separated into two categories: the "Framework" and "Functional Modules," as shown in Fig. 7. The Functional Modules include the flight parameters and prediction and propagation methods. The Framework components provide the user with communication tools for configuration manipulation of the Functional Module parameters and variables, thus providing control over the prediction process and access to the Functional Modules, Data Structures, and Utilities. The Framework is composed of three components: Command Executive, Data Structures, and Utilities. The major purpose or functionality of these are indicated in Fig. 7.

The Framework of ANOPP2 provides a platform upon which the Functional Modules communicate. Figure 8 depicts the relation between the Framework and Functional Modules (only representative prediction modules identified). The Functional Modules communicate through the Data Structures, with use of the 


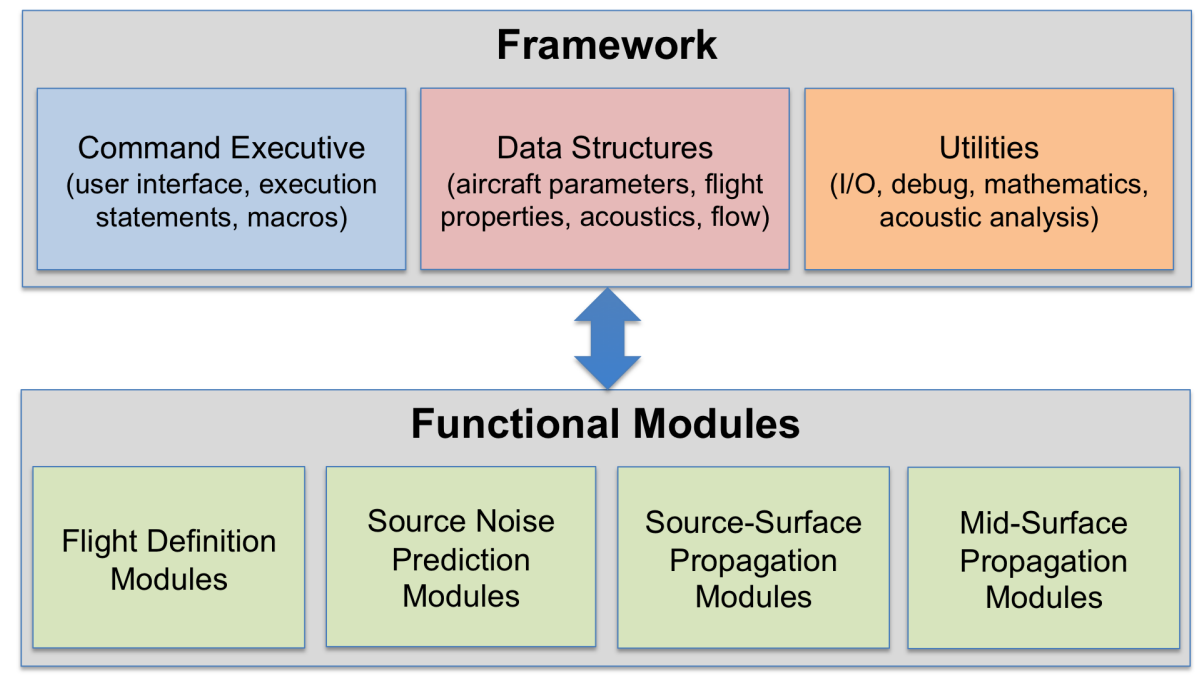

Figure 7. The key components of ANOPP2 are separated into two categories: the Framework and Functional Modules.

Utilities, as commanded by the user through the Command Executive. The Command Executive handles the input parameters, noise output, and execution environment of Functional Modules. The Data Structures, which rely on the Utilities, are provided as input to the Functional Modules. The noise predictions from the Functional Modules are placed in the Data Structures, which are accessed and provide the input to the subsequent Functional Module. This continues until the noise is calculated at the Far-Surface Data Structure. The information at this location is then processed by the Utilities, such as Acoustic Analysis, and is provided to the user.

The ANOPP2 Framework requires a language that can satisfy several major requirements, most important of which are performance, interoperability, extensibility, portability, scalability, and usability by all users. This includes not only application users, but also Functional Module developers and the NASA ANOPP2 development team. Several options were considered (including C ++ , FORTRAN, Java, and Python), but Fortran $2003 / 2008^{41}$ was found to best meet multiple requirements, namely performance and scalability for computationally intensive calculations, extensive knowledge base, legacy, interoperability with other languages including Python and $\mathrm{C}++$, extensibility due to the newly introduced Object-Oriented Programming (OOP) features, and usability by software developers internal and external to the ANOPP2 development team. The Functional Modules added to the system by external module developers are not restricted to Fortran, but may be written in other languages. This is particularly important for the Command Executive component of the Framework which must have capabilities to interface with system level software. It is important to note that, as programming languages evolve, the architecture will be updated and evolve as well.

\section{A. Flow Solutions}

ANOPP2's mixed-fidelity approach will accommodate data and inputs of multiple forms, i.e. panel method or potential flow solutions to high-fidelity, highly complex computational simulations provided by CFD. ANOPP2 provides a Data Structure for interfacing prediction and propagation methods called the Flow Solution Data Structure. Figure 9 shows an ANOPP2 configuration including Functional Modules that are high-fidelity methods requiring CFD solutions. The prediction and propagation algorithms drive the required fidelity of the Flow Solution. For example, if a prediction method requires a CFD solution with turbulence parameters then the Flow Solution input into ANOPP2 must contain turbulence quantities or data sufficient to compute the quantities. It is important to note that a single flow solution may be usable by more than one Functional Module. 


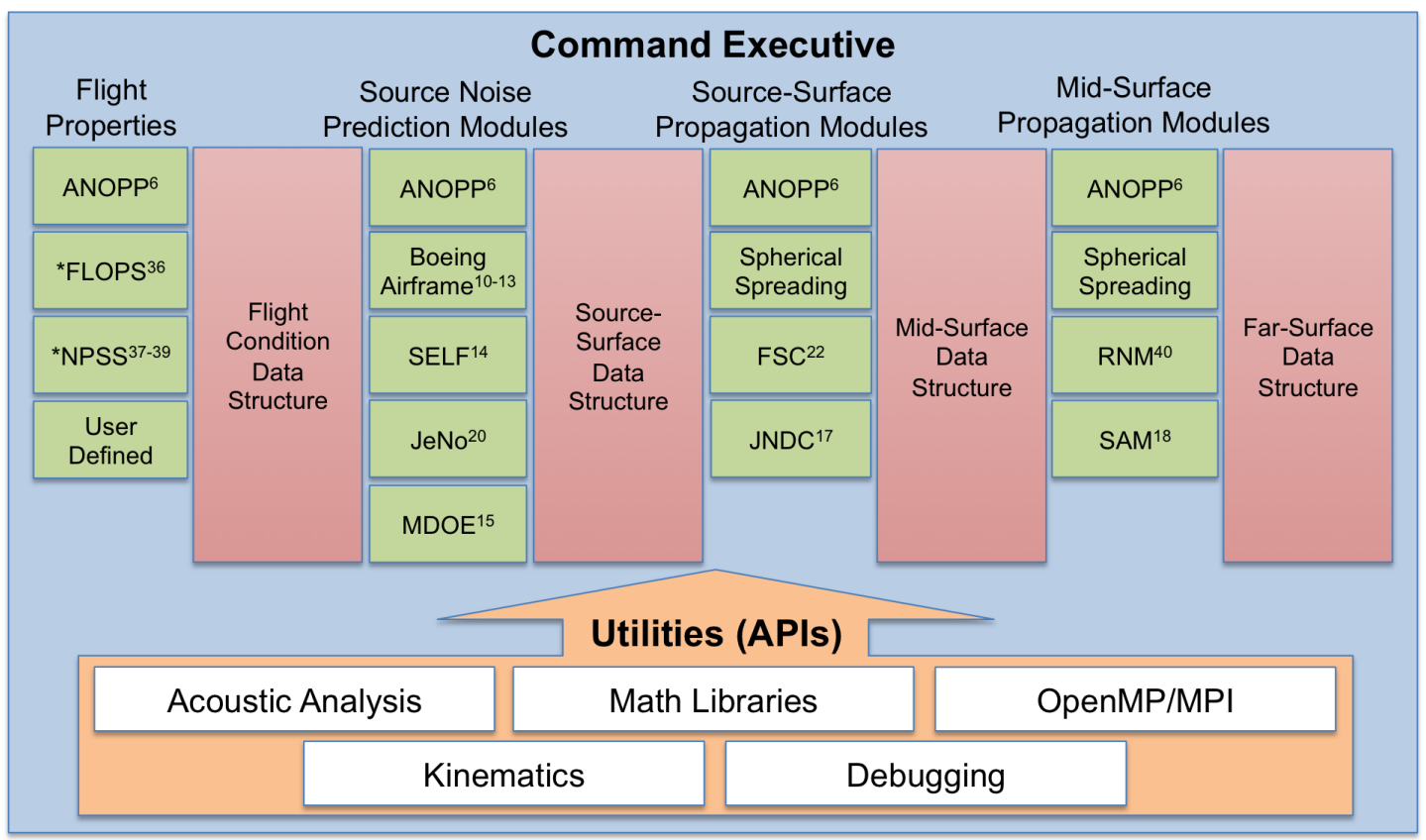

Figure 8. Schematic of ANOPP2 Framework, showing Command Executive, Utilities (APIs), and selected Functional Modules. ${ }^{6,8,9,11-22,36-40}$ The Functional Modules denoted with a ${ }^{*}$ are executed prior to ANOPP2.

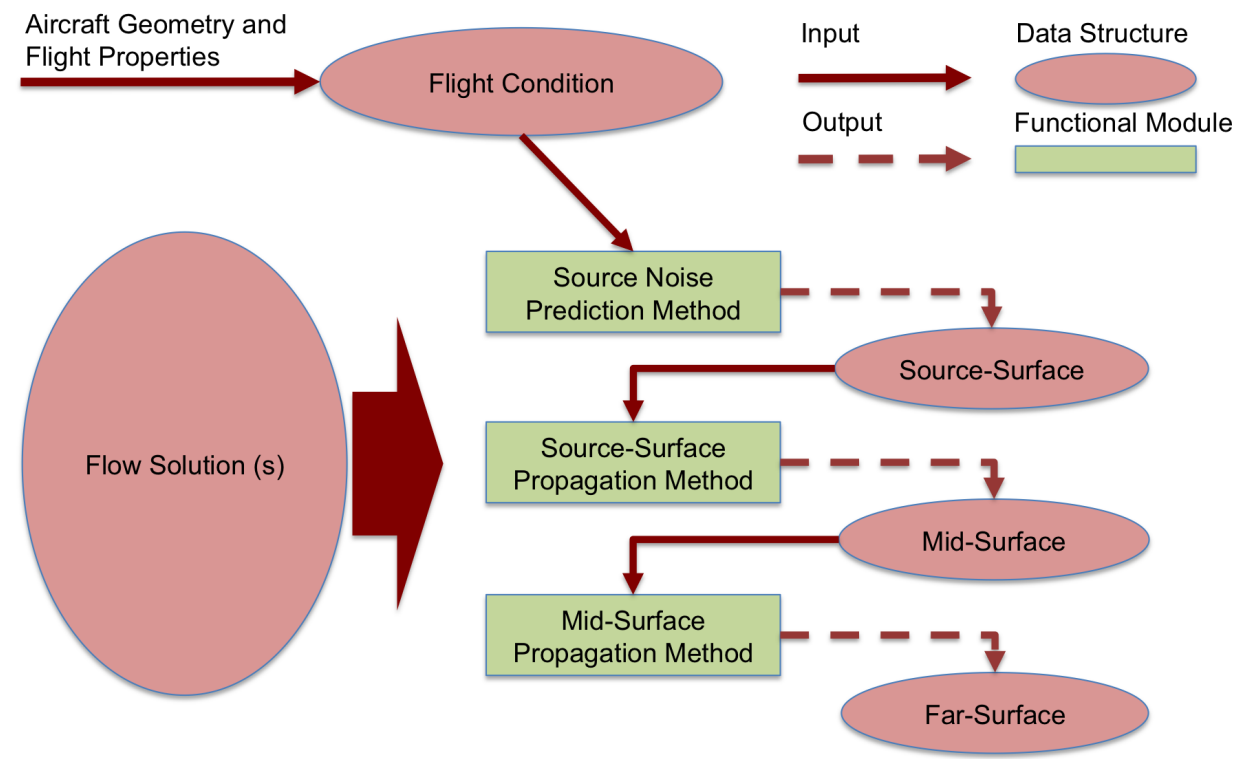

Figure 9. Demonstration of coupling CFD solutions with Functional Modules in ANOPP2. The SourceNoise Prediction Method, Source-Surface Propagation Method, and Mid-Surface Propagation Method have the ability to use CFD solutions if required via the Flow Solution Data Structure. 


\section{B. Interface With Analysis Software}

ANOPP2's design offers flexibility for the user to select the Functional Modules based on fidelity required for each stage of the prediction process. Similar to varied levels of fidelity offered for the Functional Modules, the Data Structures provide the interface to 'handle' mixed fidelity information. The interface with system analysis software, such as OpenMDAO or GEN2, occur through structures that are designed to communicate information from ANOPP2's prediction and propagation software. Figure 10 shows an ANOPP2 configuration where the Flight Condition, Flow Solutions, and Far-Surface noise results are tailored for interfacing with the OpenMDAO framework. ${ }^{24}$ These structures will facilitate the seamless integration of noise prediction with system level design software. In addition to the Data Structures, the Command Structure will interface with the system level framework through tailored Python commands.

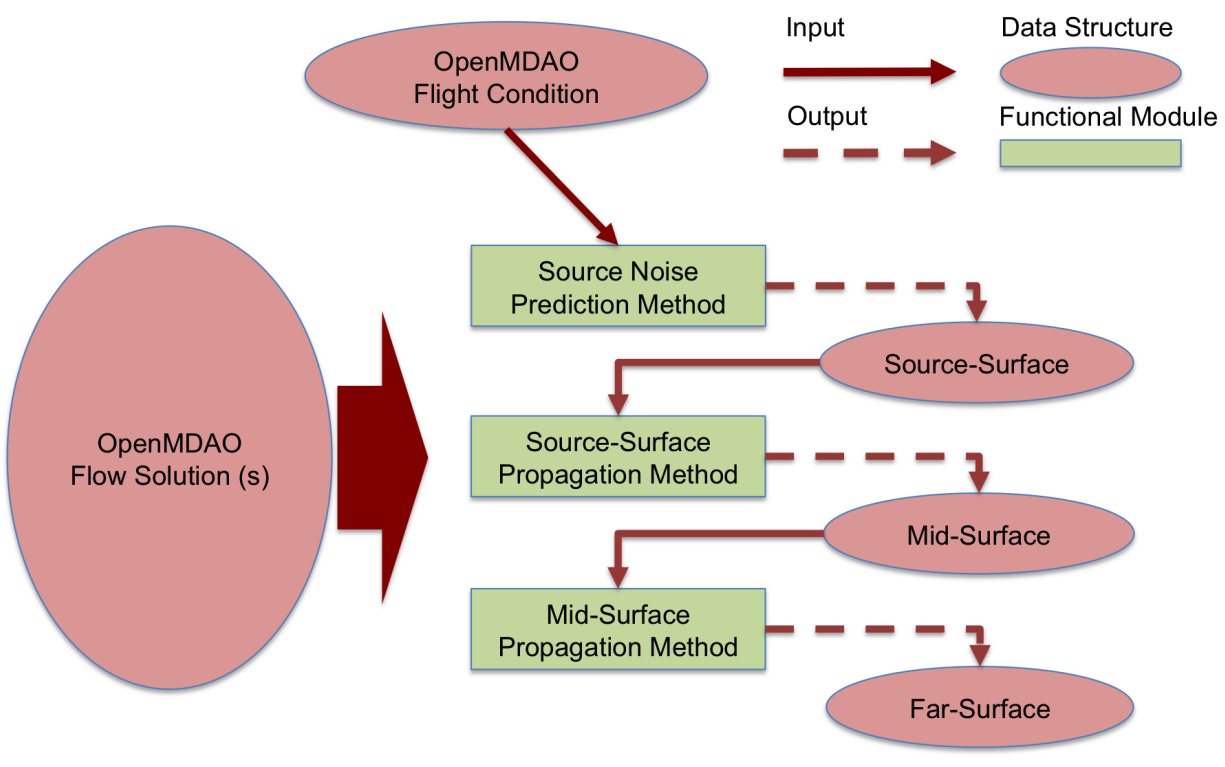

Figure 10. ANOPP2 configuration demonstrating the coupling of noise prediction with OpenMDAO framework. $^{24}$ Communications between software occur through Flight Condition, Flow Solution, and Far-Surface Data Structures.

\section{External Developers}

ANOPP2 is designed to easily implement Functional Modules developed by "External Developers" who are not part of the ANOPP2 development team. This functionality allows researchers to 'test' methods within an aircraft noise system environment even though they may not be fully developed. ANOPP2 provides a suite of tools to aid the External Developer in implementing their method within the framework. These tools include templates and a number of software utilities to streamline the implementation process. As the method matures, verification/validation and benchmark cases are added to ANOPP2 and provided with the distribution.

\section{Software Release Levels (SRLs)}

To provide a measure of confidence for each prediction and propagation method, all Functional Modules within ANOPP2 are assigned a Software Release Level (SRL) rating based on validity, stability, and documentation. The criteria for SRLs are listed in Table 1. The External Developer and the ANOPP2 development team work together to increase the SRL of the method.

\section{Application Programming Interfaces (APIs)}

The Utilities portion of ANOPP2 contains commonly used functionality, such as acoustic analysis, mathematical functions, and kinematics. These portions of the code are compiled into Application Programming 


\begin{tabular}{|l|l|}
\hline SRL 1 & $\begin{array}{l}\text { Research code with typically 1 user. } \\
\text { Limited test cases and documentation. } \\
\text { Often unstable under certain operating conditions. } \\
\text { Not supported by the ANOPP2 development team. }\end{array}$ \\
\hline SRL 2 & $\begin{array}{l}\text { Research code with multiple users. } \\
\text { Range of validity and test cases with theory and user's manual. } \\
\text { Infrequently unstable under certain operating conditions. } \\
\text { Distributed with ANOPP2 with disclaimer. Installation supported. }\end{array}$ \\
\hline SRL 3 & $\begin{array}{l}\text { Production code, including code documentation, with many users. } \\
\text { Full range of validity, code tests, validation cases, and manuals. } \\
\text { Stable under all operating conditions. } \\
\text { Integral part of ANOPP2 and fully supported by ANOPP2 development team. }\end{array}$ \\
\hline
\end{tabular}

Table 1. Criteria for ANOPP2 Functional Module Software Release Levels (SRLs).

Interfaces (APIs) and distributed with ANOPP2 as separate entities with complete documentation and are fully supported by the ANOPP2 development team. A developer may use these tools when developing new acoustic methodology independent of the ANOPP2 architecture. Use of these APIs will provide consistency with other ANOPP2 methods and ease of implementation within the framework.

\section{Documentation}

ANOPP2 will be released with a suite of documentation for aid in using, understanding, and developing ANOPP2 and its modules. The documentation provided with ANOPP2 includes: User's Manual, Theory Manual, Developer's Manual, Mini Manual, API Manuals, and an Installation Guide. The User's Manual explains how to use the software including pros and cons of choosing one Functional Module over another, limitations of the methods, interfacing with the Command Structure, and manipulating the Data Structures. The Theory Manual explains the theory behind ANOPP2 and its prediction methods. In most cases where the details of the theory exist in publications, only a brief overview of the theory and references to the original work will be provided. The Developer's Manual provides the documentation required by an External Developer to insert a method into the ANOPP2 software. The Mini Manual contains example cases consisting of input and output ANOPP2 results. Each case is of increasing complexity to acclimate the user to ANOPP2 and its functionality. The API Manuals explain the usage and theory of the library functions contained in each API. Finally, ANOPP2 is provided with an Installation Guide to help the user install and use the software on specific platforms.

\section{ANOPP2 Demonstrations}

In this section, demonstrations using ANOPP2 are given using mixed-fidelity prediction methods for various configurations. The demonstrations include a conventional aircraft using a newly developed airframe prediction method, an unconventional aircraft with two newly developed airframe methods of varied fidelity, and a prediction of noise from an isolated jet in a model-scale test configuration.

\section{A. Noise Prediction for Conventional Aircraft}

A primary objective of ANOPP2 is to retain the fidelity and speed of ANOPP, while including the capability to incorporate newer methods. The first demonstration is a prediction of noise from a conventional aircraft design, a representation of a Boeing 737-800. The Boeing 737-800 is a short-to-medium-range aircraft, with a maximum range of about $5500 \mathrm{~km}$ (3000 nautical miles). It is equipped with two CFM56-7B engines capable of $11830 \mathrm{~kg}(26091 \mathrm{lb})$ of thrust per engine at its sea level static flat rating, with a typical cruise Mach number of 0.785 . The overall length is about $39 \mathrm{~m}(129 \mathrm{ft})$ with a wingspan of over $34 \mathrm{~m}(112 \mathrm{ft})$. The FAR $36^{42}$ certification microphones and approach and departure flight path are shown in Fig. 11. The departure and approach trajectories input to $\mathrm{ANOPP}^{43}$ were simulated based on procedures described in the 
Society of Automotive Engineers (SAE) Aerospace Information Report (AIR), SAE- $1845 .{ }^{44}$ The approach has a constant-calibrated-airspeed step that is typical of airport approach on a $3^{\circ}$ glide slope to the runway threshold. The takeoff trajectory starts with the ground roll with engines at maximum takeoff rated thrust, then a rotation, followed by several climb and acceleration segments. It also includes a noise abatement throttle cutback procedure. After passing beyond the flyover observer, the engines are throttled up for the remainder of the climb.

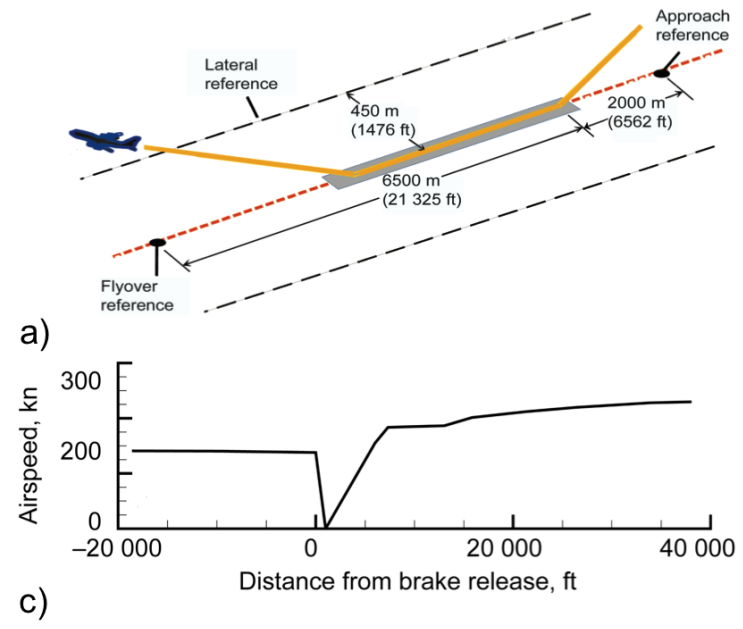

b)

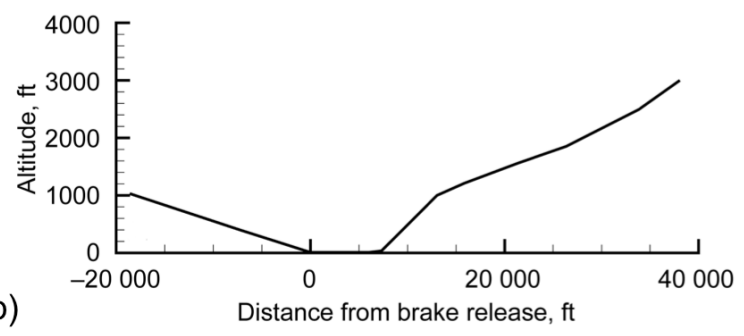

Figure 11. Conventional aircraft prediction demonstration FAR 36 microphone positions and flight path.

The noise predictions were performed by ANOPP2 executing the ANOPP system using the methods in Table 2. The inputs for the airframe noise prediction were found on the public domain Boeing website. The CFM56-7B engine was analytically modeled in the Numerical Propulsion System Simulator (NPSS) ${ }^{37-39}$ using data available from several reliable public-domain sources, such as FAA-type certification data sheets, manufacturer-provided airport planning documents, technical reports, Janes Aero Engines ${ }^{45}$ and manufacturers websites. No proprietary data were used. The source noise from the engine and airframe are propagated within ANOPP to observers located $4 \mathrm{ft}$ above the ground in accordance with the specifications for certification measurement procedure. In this configuration, ANOPP2 uses only the Far-Surface, bypassing the Source- and Mid-Surfaces to reduce computation time. Table 3 shows predictions and wall clock times using stand-alone ANOPP (Level 25) and the current ANOPP (Level 29) embedded in the ANOPP2 system. ${ }^{\mathrm{a}}$ ANOPP (Level 29) is specifically designed to communicate with ANOPP2. Differences between predicted EPNL and wall clock time are primarily due to improvements within the ANOPP system between Level 25 and 29. The ANOPP2 overhead was found to be less than 0.1 seconds for all cases. Figure 12 shows the component breakdown of noise sources on the approach condition and emission angle from the aircraft center of gravity. An emission angle of $0^{\circ}$ is directly forward of the aircraft, and $180^{\circ}$ is directly behind the aircraft. The engine sources dominate, but the airframe noise sources are significant, particularly the flap-side-edge source.

\begin{tabular}{|c|c|c|c|c|c|}
\hline Noise Source & Jet & Fan & Liner & Core & Airframe \\
\hline ANOPP Module & ST2JET $^{46}$ & HDNFAN $^{47,48}$ & TREAT $^{49}$ & GECOR $^{50}$ & FNKAFM $^{51,52}$ \\
\hline
\end{tabular}

Table 2. Prediction methods used within the ANOPP prediction system embedded within ANOPP2.

ANOPP2 includes the capability to couple current empirically-based prediction schemes with recently developed methods of higher fidelity. In this demonstration, the engine sources are predicted using those methods listed in Table 2 and the airframe noise sources are predicted using the newly developed Boeing airframe methods ${ }^{9,11-13}$ included in the ANOPP2 system. Figure 13 shows ANOPP2 predictions using a combination of ANOPP for engine sources and Boeing airframe empirical methods for airframe sources. The Boeing airframe noise predictions include all three landing gear (total landing gear noise shown), flapside-edge, slat, and trailing edge noise sources. This demonstrates the capability of ANOPP2 to combine

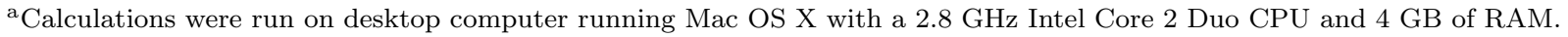




\begin{tabular}{|c|c|c|c|}
\hline EPNL (dB) / Wall Clock Time Time (sec) & Approach & Lateral & Sideline \\
\hline ANOPP (Level 25) & $95.55 / 27.55$ & $92.75 / 14.58$ & $90.75 / 14.33$ \\
ANOPP2-ANOPP (Level 29) & $95.89 / 31.22$ & $94.78 / 19.93$ & $90.40 / 20.61$ \\
\hline
\end{tabular}

Table 3. Predicted EPNL and computational time using ANOPP L25 and ANOPP L29 embedded in ANOPP2. Differences in predictions and computation time primarily due to improvements between ANOPP L25 and L29.

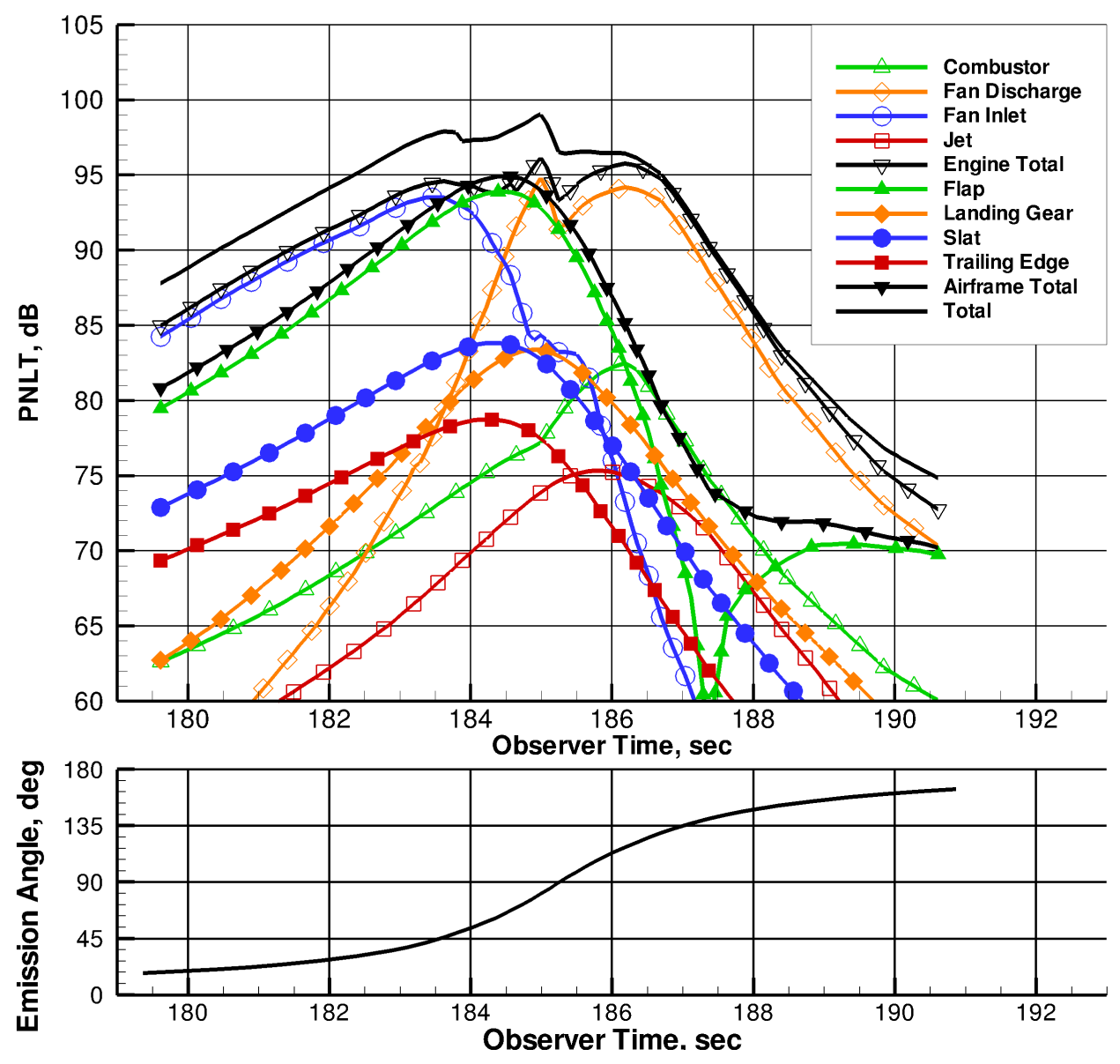

Figure 12. ANOPP2 component noise PNLT predictions for conventional aircraft design undergoing approach using ANOPP for all noise predictions. Emission angle also shown. 
benchmark and newly developed, higher-fidelity methods, allowing for direct comparisons and assessment of improved predictive capabilities. Detailed investigation of these differences are left for future studies.

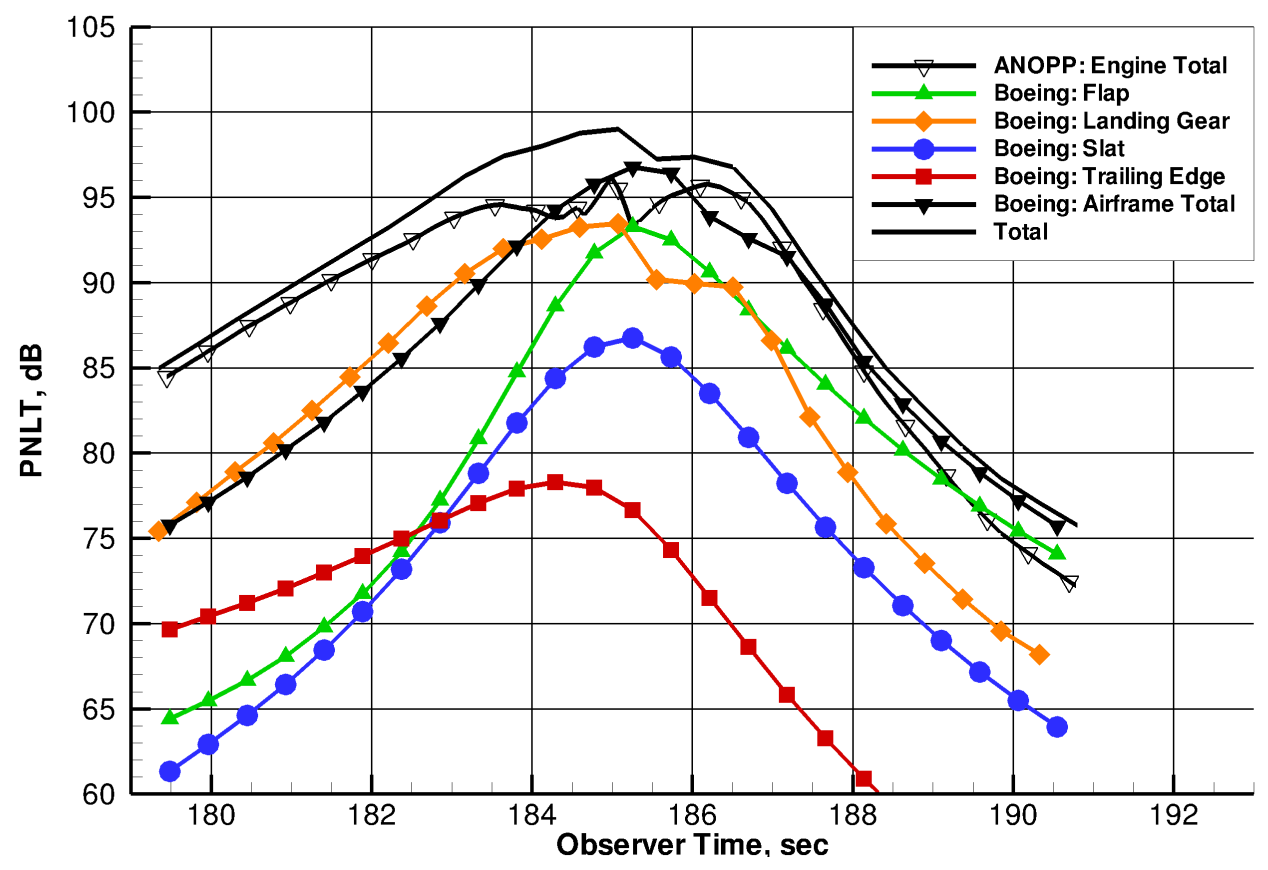

Figure 13. ANOPP2 predictions of component PNLT for conventional aircraft design undergoing approach using ANOPP for engine sources and Boeing airframe methods for airframe sources.

\section{B. Noise Prediction for Unconventional Aircraft}

In this example, ANOPP2 was used to predict noise from a Hybrid Wing Body (HWB) design, for which the airframe is shown in Fig 14. The propulsion system is not shown in Fig. 14, but is assumed to be 2 turbofan engines with the jet exit located 2 fan diameters upstream of the trailing edge between the verticals. The ANOPP2 predictions were performed with a mixture of method fidelities for an approach condition on a $3^{\circ}$ glide slope at Mach 0.21. ANOPP was used for the engine noise sources. The Boeing airframe was used for landing gear noise sources and SELF, a method based on Brooks et al. ${ }^{14}$ currently being developed at NASA Langley, was used for the trailing edge sources. As indicated in Fig. 14, the SELF method divides the airframe into streamline strips. SELF predicts the noise from each strip and sums to get the total trailing edge noise at each far-field observer. For this demonstration, the flowfield properties were determined analytically. However, the SELF prediction method is capable of extracting geometry, flow, and boundary layer properties from CFD solutions, removing the need for an empirically-based scheme for trailing edge properties. The effect of the engine/airframe noise scattering was accounted for using noise suppression maps determined from measurements. ${ }^{53}$ Direct calculation of the scattering using a higherfidelity method was not included. If this information were available, prediction of noise on the Mid-Surface would be combined with output from a scattering method and propagated to the Far-Field. Figure 15 shows preliminary ANOPP2 predictions. With this capability now available in ANOPP2, detailed examination (including validation of different approaches) is now possible.

\section{Model-Scale Experiment}

ANOPP2 has the capability to predict noise when the source and observer are fixed relative to each other. This allows for predictions to be readily compared to data obtained in model-scale experiments. Example predictions for this case are shown in Fig. 16 where ANOPP2 predictions from two jet noise methods of different fidelity are compared with scale model jet data. The experiment was conducted at the NASA Glenn Small Hot Jet Aeroacoustic Rig (SHJAR) ${ }^{54}$ with a circular (2 inch diameter) jet run with an exit Mach number of 0.7 , nozzle pressure ratio of 1.38 , and total temperature ratio of 1.0. The measurements 


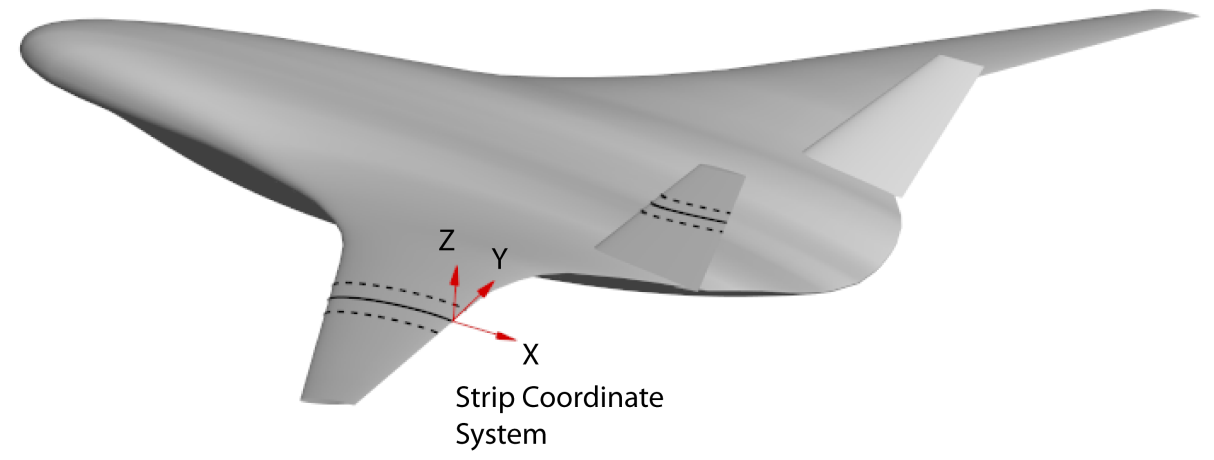

Figure 14. Notional Hybrid Wing Body (HWB) design. Also shown, local coordinate systems of SELF noise prediction method.
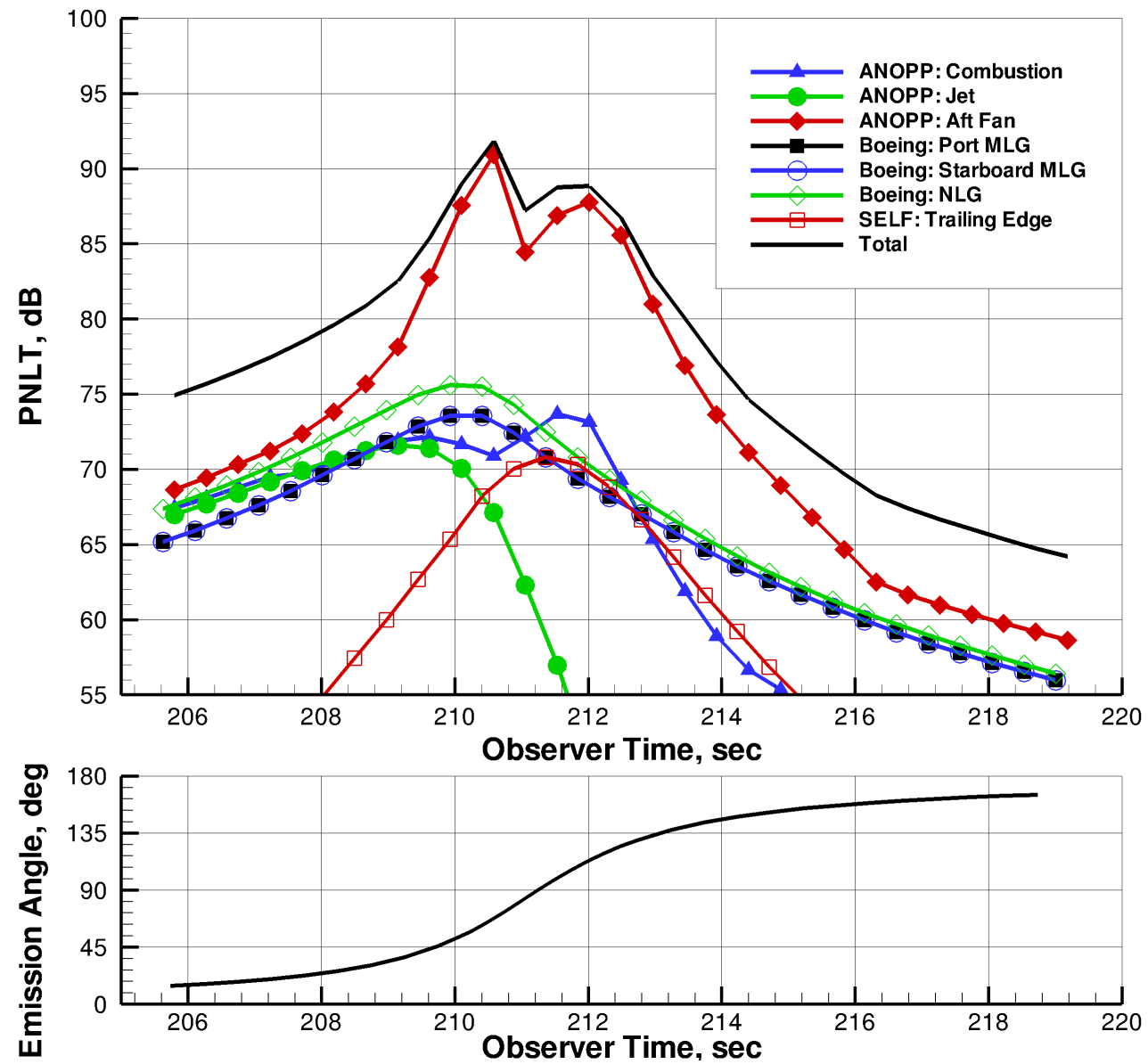

Figure 15. ANOPP2 predictions of component PNLT for unconventional aircraft design undergoing approach using ANOPP for engine sources, Boeing airframe methods for landing gear noise, and SELF for trailing edge noise. Emission angle also shown.

shown in Fig. 16 were obtained from a microphone located 90 degrees from the upstream jet exit axis at a distance of 100 jet diameters. The two predictions include a method developed by NASA that utilizes the Modern Design Of Experiments (MDOE) ${ }^{15}$ methodology as applied to jet noise (identified as ANOPP2MDOE in Fig. 16) and the NASA Glenn $\mathrm{JeNo}^{20,55}$ prediction method requiring CFD as input (identified as ANOPP2-JeNo in Fig. 16). The CFD solutions for JeNo were calculated by the NPARC Alliance Wind-US 
solver. ${ }^{56}$ The computational time ${ }^{\mathrm{b}}$ required for JeNo (not including the CFD computation) is significantly greater than that required for MDOE; however, the prediction from MDOE is only valid within the range of experimental data on which it is based and has the underlying assumption that the source is a point. The prediction using JeNo, a method based on first principles, takes much longer but provides insight into noise generating mechanisms, facilitates coupling of distributed sources with scattering algorithms, and can be used outside the current experience base.

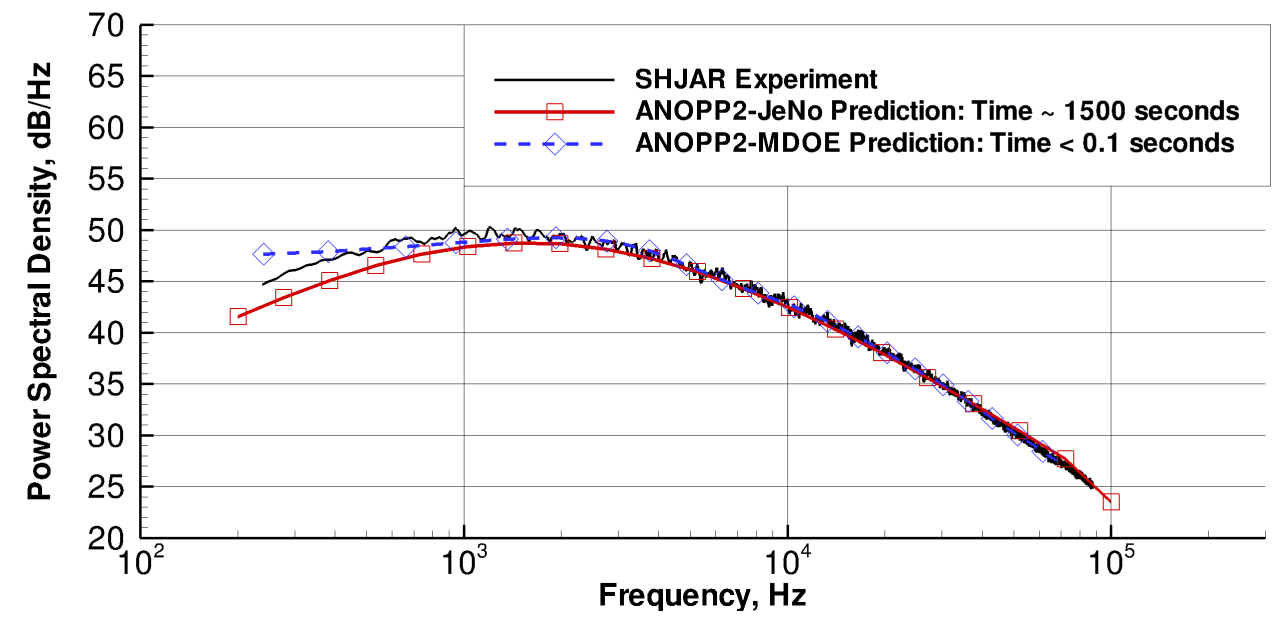

Figure 16. Preliminary ANOPP2 model-scale predictions using the MDOE ${ }^{15}$ and $\mathrm{JeNo}^{20,55}$ compared to measurements from SHJAR. ${ }^{54}$ Representative computation times are also shown. Observer located 90 degrees from jet upstream axis at a distance of 100 jet diameters.

\section{Conclusions}

This paper introduced the framework and philosophy of the next generation aircraft noise prediction program: ANOPP2. Objectives and constraints of the prediction system were summarized, thus providing definition and scope of the ANOPP2 development effort. ANOPP2's philosophy of mixed-fidelity noise prediction meets the required fidelity, extensibility, and performance criteria. The use of nested acoustic data surfaces provides the interface between prediction and propagation methods of varied fidelity. Detailed description of mixed-fidelity noise prediction application to the ANOPP2 framework design and prediction was presented. The capability of the design to accommodate distributed sources, installation effects, and the effects of the real atmosphere was shown. Coupling low and high fidelity prediction and propagation methods, embedded in ANOPP2 Functional Modules, through the use of the ANOPP2 Command Executive and Data Structures was presented. ANOPP2's ability to provide standards for the acoustic community and communicate with system analysis software was outlined and shown viable with example demonstrations. Finally, demonstrations were presented emphasizing the ability of the system to predict noise from various designs. The demonstrations included predictions of conventional aircraft designs using fast computation for system level studies, unconventional aircraft using a mixture of method fidelity, and model-scale predictions using high-fidelity and reduced-order methods.

\section{A. Future Work}

The ANOPP2 prediction system framework and Functional Modules are under active development. Many of the features presented in this paper are currently being incorporated into the system. In future works, detailed demonstrations of nested Ffowcs Williams and Hawkings surfaces will be shown, higher fidelity noise prediction and propagation schemes will be incorporated, and system validation will be performed as data becomes available.

\footnotetext{
${ }^{\mathrm{b}}$ Calculations were run on desktop computer running Mac OS X with a $2.8 \mathrm{GHz}$ Intel Core 2 Duo CPU and 4 GB of RAM.
} 


\section{Acknowledgements}

The authors would like to acknowledge Dr. Steve Miller of the Aeroacoustics Branch at NASA Langley for his help in incorporating the JeNo, MDOE, and Jet3D modules in ANOPP2 and performing the jet noise predictions in the model-scale demonstration case. The authors would also like to thank D. Stuart Pope from Analytical Services and Materials Inc. (AS\&M) and Chris S. Kilzer, Carla B. Franklin, and John W. Rawls, Jr. from the Lockheed Martin Corporation. This work was funded by NASA's Subsonic Fixed Wing (SFW) and Supersonics (SUP) Projects of the Fundamental Aeronautics Program (FAP).

\section{References}

1 "Aviation and the Environment: Airport Operations and Future Growth Present Environmental Challenges," Tech. Rep. GAO/RCED-00-153, United States General Accounting Office, Washington, D.C. 20548, August 2000.

${ }^{2}$ Hill, G. A. and Thomas, R. H., "Challenges and Opportunities for Noise Reduction Through Advanced Aircraft Propulsion Airframe Integration and Configurations," November 11-12 2004, presented at the $8^{\text {th }}$ CEAS Workshop on Aeroacoustics of New Aircraft and Engine Configurations.

${ }^{3}$ Collier, F. S., "Environmentally Responsible Aviation (ERA) Project," September 29-October 1 2009, Atlanta, Georgia. Presented at the NASA Fundamental Aeronautics Program, Third Annual Technical Conference.

${ }^{4}$ Thomas, R. H., Burley, C. L., and Olson, E. D., "Hybrid Wing Body Aircraft System Noise Assessment With Propulsion Airframe Aeroacoustic Experiments," June 7-9 2010, AIAA Paper No. 2010-3913, presented at the 16 ${ }^{\text {th }}$ AIAA/CEAS Aeroacoustics Conference.

${ }^{5}$ Raney, J. P., "Development of a New Computer System for Aircraft Noise Prediction," March 24-26 1975, AIAA Paper No. 75-536, presented at the $2^{\text {nd }}$ Aero-acoustics Conference.

${ }^{6}$ Zorumski, W. E., "Aircraft Noise Prediction Program Theoretical Manual, Parts 1 and 2," Tech. Rep. NASA/TM83199-PT-1 and PT-2, National Aeronautics and Space Administration, Langley Research Center, Hampton, VA., February 1982.

${ }^{7}$ Smith, M., Carrilho, J., Molin, N., Piet, J.-F., and Chow, L., "Modeling Landing Gear Noise With Installation Effects," May 21-23 2007, AIAA Paper No. 2007-3472, $13^{\text {th }}$ AIAA/CEAS Aeroacoustics Conference (28 ${ }^{\text {th }}$ AIAA Aeroacoustics Conference).

${ }^{8}$ Lopes, L. V., Brentner, K. S., and Morris, P. J., "Airframe Noise Prediction with Installed Landing Gear for a Complete Aircraft," May 11-13 2009, AIAA Paper No. 2009-3155, $15^{t h}$ AIAA/CEAS Aeroacoustics Conference (30 ${ }^{t h}$ AIAA Aeroacoustics Conference).

${ }^{9}$ Guo, Y., "A Study on Local Flow Variations for Landing Gear Noise Research," May 5-7 2008, AIAA Paper No. 20082915, $14^{t h}$ AIAA/CEAS Aerodynamics Conference (29 $9^{t h}$ AIAA Aeroacoustics Conference).

${ }^{10}$ Thomas, R. H., "Subsonic Fixed Wing Project N+2 Noise Goal Summary," December 4-5 2007, Cleveland, Ohio. Presented at the NASA Acoustics Technical Working Group. Available on the Langley Technical Report Server (LTRS).

${ }^{11}$ Guo, Y., "Flap Side Edge Noise Prediction Model," Tech. Rep. NASA CR NNL07AA03A, National Aeronautics and Space Administration, July 2009.

${ }^{12}$ Guo, Y., "On Trailing Edge Noise Modeling and Prediction for Aircraft High Lift Wings," Tech. Rep. NASA CR NNL07AA03A, National Aeronautics and Space Administration, January 2010.

${ }^{13}$ Guo, Y., "Aircraft Slat Noise Modeling and Prediction," June 7-9 2010, AIAA Paper No. 2010-3837, presented at the $16^{\text {th }}$ AIAA/CEAS Aeroacoustics Conference.

${ }^{14}$ Brooks, T. F., Pope, S. D., and Marcolini, M. A., "Airfoil Self-Noise and Prediction," NASA RP 1218, NASA, July 1989.

${ }^{15}$ Henderson, B., "An MDOE Investigation of Chevrons for Supersonic Jet Noise Reduction," June 7-9 2010, AIAA Paper No. 2010-3926, $16^{\text {th }}$ AIAA/CEAS Aeroacoustics Conference.

${ }^{16}$ Whitfield, C. E., Mani, R., and Gliebe, P. R., "High Speed Turboprop Aeroacoustic Study (Counterrotation): Volume I - Model Development," Tech. Rep. NASA CR 185241, National Aeronautics and Space Administration, July 1990.

${ }^{17}$ Papamoschou., D., "Prediction of Jet Noise Shielding," January 4-7 2010, AIAA Paper No. 2010-653, 48 ${ }^{\text {th }}$ AIAA Aerospace Sciences Meeting Including the New Horizons Forum and Aerospace Exposition.

${ }^{18}$ Gabillet, Y., Schroeder, H., Daigle, G. A., and L'Expérance, A., "Application of the Gaussian Beam Approach to Sound Propagation in the Atmosphere: Theory and Experiments," Journal of the Acoustical Society of America, Vol. 93, No. 6, 1993, pp. 3105-3116.

${ }^{19}$ Dunn, M. H., "Computational Methods in the Prediction of Advanced Subsonic and Supersonic Propeller Induced Noise - ASSPIN Users Manual," Tech. Rep. NASA CR 187559, National Aeronautics and Space Administration, April 1992.

${ }^{20}$ Khavaran, A., Bridges, J., and Georgiadis, N., "Prediction of Turbulence-Generated Noise in Unheated Jets Part 1: JeNo Technical Manual (Version 1.0)," Tech. Rep. NASA/TM-2005-21387, National Aeronautics and Space Administration, 2005.

${ }^{21}$ Hunter, C., An Approximate Jet Noise Prediction Method Based on Reynolds-Averaged Navier-Stokes, Ph.D. thesis, The George Washington University, 2002.

${ }^{22}$ Tinetti, A. F., Dunn, M. H., and Pope, D. S., Fast Scattering Code (FSC) User's Manual, Version 2.0, October 2006, NASA CR 2006-214510.

${ }^{23}$ Kirby, M. R. and Mavris, D. N., "The Environmental Design Space," September 14-19 2008, AIAA Paper No. 2008-8875, $26^{\text {th }}$ Congress of International Council of Aeronautical Sciences (ICAS).

${ }^{24}$ Moore, K. T., Naylor, B. A., and Gray, J. S., "The Development of an Open Source Framework for Multidisciplinary Analysis \& Optimization," September 10-12 2008, AIAA Paper No. 2008-6069 , presented at the 12 ${ }^{\text {th }}$ AIAA/ISSMO Multidisciplinary Analysis and Optimization Conference. 
${ }^{25}$ Wells, D. P. and Olson, E. D., "Hybrid Wing Body Planform Design with Vehicle Sketch Pad," January 4-7 2011, AIAA Paper No. 2011-360, $49^{t h}$ AIAA Aerospace Sciences Meeting including the New Horizons Forum and Aerospace Exposition.

${ }^{26}$ Message Passing Interface Forum: http://www.mpi-forum.org.

${ }^{27}$ The OpenMP API Specifications for Parallel Programming: http://openmp.org.

${ }^{28}$ Ffowcs Williams, J. E. and Hawkings, D. L., "Sound Generated by Turbulence and Surfaces in Arbitrary Motion," Philosophical Transactions of the Royal Society, Vol. A264, No. 1151, 1969, pp. 321-342.

${ }^{29}$ Farassat, F., "Linear Acoustic Formulas for Calculation of Rotating Blade Noise," AIAA Journal, Vol. 19, No. 9, September 1981, pp. 1122-1130.

${ }^{30}$ Farassat, F., Dunn, M. H., and Spence, P. L., "Advanced Propeller Noise Prediction in the Time Domain," AIAA Journal, Vol. 30, No. 9, September 1992, pp. 2337-2340.

${ }^{31}$ Lockard, D. P., "A Comparison of Ffowcs Williams - Hawkings Solvers for Airframe Noise Applications," June 17-19 2002, AIAA Paper No. 2002-2580, $8^{\text {th }}$ AIAA/CEAS Aeroacoustics Conference and Exhibit.

${ }^{32}$ Brès, G. A., Brentner, K. S., Perez, G., and Jones, H. E., "Maneuvering Rotorcraft Noise Prediction," Journal of Sound and Vibration, Vol. 275, No. 3-5, August 2004, pp. 719-738.

${ }^{33}$ Perez, G., Brentner, K. S., Brès, G. A., and Jones, H. E., "A First Step Toward the Prediction of Rotorcraft Maneuvering Noise," Journal of the American Helicopter Society, Vol. 50, No. 3, July 2005, pp. 230-237.

${ }^{34}$ Farassat, F. and Brentner, K. S., "Supersonic Quadrupole Noise Theory For High-Speed Helicopter Rotors," Journal of Sound and Vibration, Vol. 218, No. 3, 1998, pp. 481-500.

${ }^{35}$ Bodony, D. and Lele, S., "Current Status of Jet Noise Predictions Using Large-Eddy Simulation," AIAA Journal, Vol. 46, No. 2, 2008, pp. 364-380.

${ }^{36}$ McCullers, L. A., "FLOPS User's Guide," Tech. Rep. Release 6.02, NASA Langley Research Center, March 2003.

${ }^{37}$ Lytle, J., Follen, G., Naiman, C., Evans, A., Veres, J., Owen, K., and Lopez, I., "Numerical Propulsion System Simulation (NPSS) 1999 Industry Review," Tech. Rep. NASA/TM-209795, National Aeronautics and Space Administration, August 2000.

${ }^{38}$ Lytle, J. K., "The Numerical Propulsion System Simulation: An Overview," Tech. Rep. NASA/TM-2000-209915, National Aeronautics and Space Administration, June 2000.

${ }^{39}$ Jones, S. M., "An Introduction to Thermodynamic Performance Analysis of Aircraft Gas Turbine Engine Cycles Using the Numerical Propulsion System Simulation Code," Tech. Rep. NASA/TM-2007-214690, National Aeronautics and Space Administration, March 2007.

${ }^{40}$ Conner, D. A., Burley, C. L., and Smith, C. D., "Flight Acoustic Testing and Data Acquisition for the Rotor Noise Model (RNM)," May 9-11 2006, Presented at American Helicopter Society 62nd Annual Forum.

${ }^{41}$ American National Standards Institute (ANSI), "Information Technology - Programming Languages - Fortran - Part 1: Base Language," Tech. Rep. BS ISO/IEC 1539-1:2004(E), Revised 2010.

${ }^{42}$ Federal Aviation Administration (FAA), "Noise Standards: Aircraft Type and Airworthiness Certification," July 2003.

${ }^{43}$ Dahl, M.D. (ed.), "Assessment of NASA's Aircraft Noise Prediction Capability," Tech. Rep. NASA TP-2011-215653, 2011.

${ }^{44}$ Society of Automotive Engineers (SAE), "Procedure for the Calculation of Airplane Noise in the Vicinity of Airports," Tech. Rep. SAE Aerospace Information Report (AIR), January 1986.

${ }^{45}$ Jane's: Defense \& Security Intelligence \& Analysis: http://jae.janes.com.

${ }^{46}$ Stone, J. R., Kresja, E. A., and Clark, B. K., "Jet Noise Modeling for Suppressed and Unsuppressed Aircraft in Simulated Flight," Tech. Rep. NASA/TM-2009-215524, National Aeronautics and Space Administration, March 2009.

${ }^{47}$ Heidmann, M. F., "Interim Prediction Method for Fan Compressor Source Noise," Tech. Rep. NASA TM X-71763, National Aeronautics and Space Administration, 1979.

${ }^{48}$ Kontos, K., Janardan, B., and Gliebe, P., "Improved NASA-ANOPP Prediction Computer Code for Advanced Subsonic Propulsion Systems," Tech. Rep. NASA CR-195480, National Aeronautics and Space Administration, August 1996.

${ }^{49}$ Kontos, K. B., Kraft, R. E., and Gliebe, P. R., "Improved NASA-ANOPP Noise Prediction Computer Code for Advanced Subsonic Propulsion Systems. Volume 2: Fan Suppression Model Development," Tech. Rep. NASA CR-202309, National Aeronautics and Space Administration, December 1996.

${ }^{50}$ Society of Automotive Engineers (SAE), "Gas Turbine Jet Exhaust Noise Prediction," Tech. Rep. SAE Aerospace Recommended Practice ARP876, January 1994.

${ }^{51}$ Fink, M. D., "Airframe Noise Prediction Method," Tech. Rep. FAA RD-77-29, March 1977.

${ }^{52}$ Fink, M. D., "Noise Component Method for Airframe Noise," Journal of Aircraft, Vol. 16, No. 10, 1979, pp. 659-665.

${ }^{53}$ Czech, M. J., Thomas, R. H., and Elkoby, R., "Propulsion Airframe Aeroacoustic Integration Effects for a Hybrid Wing Body Aircraft Configuration," June 7-9 2010, AIAA Paper No. 2010-3912, presented at the $16^{\text {th }}$ AIAA/CEAS Aeroacoustics Conference.

${ }^{54}$ Bridges, J. and Brown, C. A., "Validation of the Small Hot Jet Acoustic Rig for Aeroacoustic Research," May 23-25 2005, AIAA Paper No. 2005-2846, presented at the $11^{\text {th }}$ AIAA/CEAS Aeroacoustics Conference.

${ }^{55}$ Khavaran, A., Wolter, J. D., and Koch, L. D., "Prediction of Turbulence-Generated Noise in Unheated Jets Part 2: JeNo User's Manual (Version 1.0)," Tech. Rep. NASA/TM-2009-213827, National Aeronautics and Space Administration, 2009.

${ }^{56}$ Bush, R. H., Power, G. D., and Towne, C. E., "Wind: Production Flow Solver of the NPARC Alliance," January 12-15 1998, AIAA Paper No. 98-0935, presented at the $36^{t h}$ AIAA Aerospace Sciences Meeting and Exhibit. 